\title{
The role of processing route on the microstructure of 14YWT nanostructured ferritic alloy
}

\author{
B. Mazumder ${ }^{1}$, C. M. Parish ${ }^{2}$, H. Bei ${ }^{2}$, and M. K. Miller ${ }^{1}$ \\ ${ }^{1}$ Center for Nanophase Materials Sciences, \\ Oak Ridge National Laboratory, Oak Ridge, TN 37831, U.S.A \\ ${ }^{2}$ Materials Science and Technology Division, \\ Oak Ridge National Laboratory, Oak Ridge, TN 37831, U.S.A.
}

\begin{abstract}
Nanostructured ferritic alloys have outstanding high temperature creep properties and enhanced tolerance to radiation damage over conventional ferritic alloys. To achieve these properties, NFAs are fabricated by mechanical alloying of metallic and yttria powders. Atom probe tomography has demonstrated that milling times of at least $40 \mathrm{~h}$ are required to produce a uniform distribution of solutes in the flakes. After milling and hot extrusion, the microstructure consists of $\alpha$-Fe, high number densities of Ti-Y-O-vacancyenriched nanoclusters, and coarse $\mathrm{Y}_{2} \mathrm{Ti}_{2} \mathrm{O}_{7}$ and $\mathrm{Ti}(\mathrm{O}, \mathrm{C}, \mathrm{N})$ precipitates on the grain boundaries. In contrast, the as-cast condition consists of $\alpha$-Fe with 50-100 $\mu \mathrm{m}$ irregularly-shaped $\mathrm{Y}_{2} \mathrm{Ti}_{2} \mathrm{O}_{7}$ pyrochlore precipitates with smaller embedded precipitates with the $\mathrm{Y}_{3} \mathrm{Al}_{5} \mathrm{O}_{12}$ (yttrium-aluminum garnet) crystal structure indicating that this traditional processing route is not a viable approach to achieve the desired microstructure. The nano-hardnesses were also substantially different, i.e., 4 and $8 \mathrm{GPa}$ for the as-cast and as-extruded conditions, respectively. These variances can be explained by the microstructural differences and the effects of the high vacancy content introduced by mechanical alloying, and the strong binding energy of vacancies with $\mathrm{O}, \mathrm{Ti}$, and $\mathrm{Y}$ atoms that retard diffusion.
\end{abstract}

Keywords: nanostructured ferritic alloys, atom probe tomography, vacancy, nanoclusters

Corresponding author: mazumderb@ornl.gov

Center for Nanophase Materials Sciences, P. O. Box 2008, Building 4500S, Oak Ridge National Laboratory, Oak Ridge, TN 37831-6139, U.S.A

Notice: This submission was sponsored by a contractor of the United States Government under contract DE-AC05-00OR22725 with the United States Department of Energy. The United States Government retains, and the publisher, by accepting this submission for publication, acknowledges that the United States Government retains, a nonexclusive, paid-up, irrevocable, worldwide license to publish or reproduce the published form of this submission, or allow others to do so, for United States Government purposes. 


\section{Introduction}

The microstructure of nanostructured ferritic alloys (NFAs), such as 12YWT and 14YWT, results in excellent creep and radiation tolerance properties, due to a high density of ultrafine intragranular Y-Ti-Oenriched nanoclusters $(\mathrm{NCs})$, nanosize grains $(<500 \mathrm{~nm})$ as well as precipitation on and solute segregation to grain boundaries (GBs) [1-5]. However, the formation of this unique microstructure is highly dependent upon the processing path [6]. This uniqueness is because of synergies between the Ti, Y, O, and vacancy species in non-equilibrium arrangements within the matrix resulting from mechanical alloying. Although the 12YWT and 14YWT NFAs [7-10] were developed prior to the first-principals calculations of Fu et al. [11-12], these calculations indicated the potential of yttrium additions for further improving the bonding energy of Ti-O-vacancy clusters, and are supported by experiments [13].

As yttrium is almost insoluble in iron, yttrium-doped iron alloys cannot be produced by traditional casting methods $[14,15]$. In addition, the liquid phase cannot be used to homogenize the distribution of solutes. Therefore, mechanical alloying [16-18] is a viable processing route for such alloys. This alternative route introduces new parameters on the optimization of the alloy design. In particular, the milling time will have a strong influence on the initial distribution of the solutes, particularly yttrium and oxygen [19]. The tensile properties of a 14Cr NFA are directly associated with the microstructural changes that arise during mechanical alloying, such as the attrition time [19], which provide the starting structure for thermomechanical treatment (extrusion, rolling, etc.). Short milling times may not be sufficient to redistribute the solute atoms in all the yttria particles within the solid solution, whereas overly long milling times add unnecessary expense to the fabrication, and introduce additional elements, such as carbon, from wear of the components of the attritor mill $[16,20]$. Microstructural studies of these alloys for long milling times (i.e. > 20 hours) have been reported [6, 21-25] however, only limited 3dimensional visualizations of the size and distribution of the NCs and coarse precipitates in the microstructures have been reported for short milling times (i.e. $<20$ hours) [25]. The purpose of this 
study is to explore the solute distribution in consolidated bars of 14YWT produced from mechanically alloyed 14YWT flakes with different milling times, and compare to a melted (non-NC-bearing) condition of the same alloy, in order to determine the underlying atomistic processes that result in the extruded product's excellent final properties.

\section{Experimental}

\subsection{Material}

The NFA was fabricated by mechanically alloying a master Fe-Cr-W-Ti alloy powder with $\mathrm{Y}_{2} \mathrm{O}_{3}$ powder. The alloy was characterized after two different sets of conditions. The first condition, hereafter referred to as the as-cast condition, was a mechanically alloyed and consolidated 14YWT specimen that was melted in a differential scanning calorimeter (DSC) and cooled to room temperature. The melting point of the ascast specimen was estimated from the DSC data to be $\approx 1515{ }^{\circ} \mathrm{C}$. The second condition consisted of a series of specimens that were prepared from flakes mechanical alloyed for 5,20 or $40 \mathrm{~h}$ in the attritor mill, consolidated by hot extrusion at $850^{\circ} \mathrm{C}$, and aged for $1 \mathrm{~h}$ at $1000{ }^{\circ} \mathrm{C}$. The composition of the consolidated 14YWT NFA used for this study [21] is given in Table 1. The use of 5, 20 and $40 \mathrm{~h}$ as sample name indicates the milled, extruded and annealed sample conditions.

\subsection{Nanohardness}

A Nanoindenter-XP system with a Berkovich tip was used to measure the hardness and modulus of the specimens. Load (P) and displacement (h) were continuously recorded up to a maximum applied load

$\left(\mathrm{P}_{\max }\right)$ of $1.5 \mathrm{mN}$ at a constant indentation strain rate $(\mathrm{dP} / \mathrm{dt}) / \mathrm{P}$ of $0.05 \mathrm{~s}^{-1}$, which resulted in a maximum depth of $\sim 100 \mathrm{~nm}$. The hardness and modulus were determined from the $\mathrm{P}-\mathrm{h}$ unloading curves by the Oliver-Pharr method [26].

\subsection{Specimen preparation}


The extruded specimens were fabricated into atom probe tomography (APT) needle-shaped specimens by standard electropolishing methods [27-28]. Some electropolished specimens were also refined with an annular Ga ion milling in a FEI Nova 200 dual beam scanning electron microscope (SEM) and focused ion beam (FIB) technique [29-30]. In the as-cast material, site-specific APT specimens were fabricated by a lift-out method from a mechanically-polished surface, the details of which can be found elsewhere [2930].

\subsection{Microstructural characterization methods}

Electron microscopy and electron backscatter diffraction (EBSD) was performed in a JEOL JSM6500F field-emission SEM, equipped with an EDAX Hikari EBSD camera and EDAX Apollo 40 silicon drift detector (SDD) energy dispersive spectrometer (EDS). APT was performed in a CAMECA instruments Inc. LEAPTM 4000X HR. All APT specimens were analysed in laser mode (with a focused UV laser beam) with a specimen temperature of $30 \mathrm{~K}$, a pulse repetition frequency of $200 \mathrm{kHz}$, a pulse laser energy of $100 \mathrm{pJ}$, and an average ion detection rate of $0.2 \%$. All APT composition estimates are given in atomic percent.

\section{Results}

\subsection{Hardness}

The nanohardness of the as-cast alloy was $4.0 \pm 0.4 \mathrm{GPa}$ and the modulus was $188 \pm 14 \mathrm{GPa}$. In comparison, the nanohardness of the extruded alloy was $8.2 \pm 0.6 \mathrm{GPa}$ (after a short anneal at $75^{\circ} \mathrm{C}$ ) with modulus of $269 \pm 28 \mathrm{GPa}$. Therefore, the nanohardness and modulus of the as-cast condition decreased by approximately $50 \%$ and $30 \%$, respectively, compared to the extruded condition which is indicative of variances in the resulting microstructures of the two processing routes.

\subsection{Microstructure}

\subsubsection{As-cast condition}


As indicated from the nanohardness results, the microstructure of the as-cast condition is substantially different from the as-extruded 14YWT material. APT of the ferrite matrix did not reveal any fine precipitates or NCs ; however the ferrite was significantly depleted in the solutes, i.e., $0.07 \pm 0.01 \% \mathrm{Ti}$, $0.03 \pm 0.01 \% \mathrm{Y}$ and $0.04 \pm 0.01 \% \mathrm{O}$, compared to the base alloy bulk chemistry. The grain size of the ascast condition was considerably larger, i.e., in the mm range, compared to the 40-200 $\mathrm{nm}$ grain size of the as-extruded condition. A finer-scale, 3-15 $\mu \mathrm{m}$, Y-Ti-Al-O phase was evident in the interior of an irregularly-shaped coarse 50-100 $\mu \mathrm{m}$ Ti-Y-O phase, as shown in the 2-dimensional tri-colour multivariate statistical analysis (MVSA) [31] identification of the phases present with EDS X-ray spectra in Fig. 1. EDS analysis indicated that the composition of the pyrochlore-like phase had an approximate $\mathrm{Y}_{1.5} \operatorname{Ti}_{2} \mathrm{O}_{5.5}$ atomic ratio $(\sim 15 \%$ at. $\% \mathrm{Y}, \sim 20 \% \mathrm{Ti}$, and $\sim 65 \% \mathrm{O})$, with a trace level of $\mathrm{Al}$, and the YAG-like phase had an $\mathrm{Y}_{3} \mathrm{Al}_{5} \mathrm{O}_{12}$ atomic ratio $(\sim 30 \%$ at. $\% \mathrm{Al}, \sim 15 \% \mathrm{Y}$ and $\sim 55 \% \mathrm{O})$ with a trace amount of Ti. A backscattered electron (BSE) image of the as-cast condition reveals a ferrite matrix with isolated islands of coarse oxide precipitates (Fig. 2). The electron backscatter Kikuchi patterns of these Ti-Y-O and Y-TiAl-O oxides, Fig. 2, were consistent with the crystal structures of $\mathrm{Y}_{2} \mathrm{Ti}_{2} \mathrm{O}_{7}$ (pyrochlore) and $\mathrm{Y}_{3} \mathrm{Al}_{5} \mathrm{O}_{12}$ (yttrium-aluminum garnet - YAG) phases, respectively, but other phases with similar interplanar angles could be possible. In comparison, an APT composition estimate of the interior of the pyrochlore phase was $17.7 \pm 0.016$ at. $\% \mathrm{Ti}, 11.2 \pm 0.04 \% \mathrm{Y}, 68.9 \pm 0.03 \% \mathrm{O}$, and $0.2 \pm 0.01 \% \mathrm{Al}$, and that of the YAGlike phase was $19.8 \pm 0.1$ at. $\% \mathrm{Al}, 15.2 \pm 0.1 \% \mathrm{Y}, 59.1 \pm 0.1 \% \mathrm{O}$, and $5.9 \pm 0.02 \% \mathrm{Ti}$. These values are in reasonable agreement with the prototypical composition of their respective phases, assuming that the $\mathrm{Ti}$ is included in the $\mathrm{Al}$ estimate for the YAG phase, as shown in Table 2. Because the Al content of the premelted base alloy was assayed as 0.04 at. \% Al, it is likely that the high level of $\mathrm{Al}$ in the YAG phase arose from the alumina crucible used to melt the alloy.

\subsubsection{5, 20 and $40 \mathrm{~h}$ 14YWT milling times}

The microstructures of the NFA after the three milling times followed by extrusion and aging for $1 \mathrm{~h}$ at $1000{ }^{\circ} \mathrm{C}$ are shown in Fig. 3. The 3\% Ti concentration isosurfaces reveal the formation of some Ti-O-C- 
$\mathrm{N}$-enriched precipitates in all three conditions, but the size of the irregularly-shaped precipitates in the $5 \mathrm{~h}$ milled specimen was significantly coarser than the 20 and $40 \mathrm{~h}$ milled specimens. The number densities of the precipitates for the 5,20 and $40 \mathrm{~h}$ milled conditions were estimated to be $\sim 7.5 \times 10^{22} \mathrm{~m}^{-3}, \sim 2.3 \times 10^{23}$ $\mathrm{m}^{-3}$ and $\sim 1 \times 10^{24} \mathrm{~m}^{-3}$, respectively. For all three milling times, no evidence was found of any remnants of yttria powder in the matrix. From APT measurements, the compositions of the ferrite phase from different regions of each of the three different milling times are estimated and listed in Table 1. These results indicate marked variations in the solute contents, especially in the shorter milling time conditions. In the 40h volume, the segregation of $\mathrm{W}$ atoms to the GBs was observed, Fig 3c . Some $\mathrm{C}$ and $\mathrm{Cr}$ segregation to the GB was also observed, which has been previously observed for this processing condition $[21,32,33$, 34]. Other volumes of 40,20 , and $5 \mathrm{~h}$ specimens showed similar segregation; the $5 \mathrm{~h}$ material's grains were so large only a single GB was captured in atom probe, however. This segregation likely occurs during post-mechanical alloying thermomechanical processing (i.e., extrusion and annealing) and is likely a common occurrence.

Proximity histogram across the interfaces of two of the coarse precipitates in the material milled for $5 \mathrm{~h}$, shown in Fig. 3a, are shown in Fig 4. APT results from two additional regions of the alloy milled for $5 \mathrm{~h}$ are shown in Fig. 5. In this data, a coarse, $\sim 25 \mathrm{~nm}$ by $\sim 10 \mathrm{~nm}$, Ti-Y-O-enriched particles was revealed, within which the $\mathrm{Y}$ and $\mathrm{O}$ were found to be concentrated at its center, as shown in the proximity histogram in Fig. 6a. This central Y-enriched region was found to have a composition of $15.7 \pm 1.5$ at. \% Fe, $15 \pm 0.5 \% \mathrm{Cr}, 12.5 \pm 0.3 \% \mathrm{Y}, 1 \pm 0.3 \% \mathrm{~W}, 20.6 \pm 0.5 \% \mathrm{Ti}, 15.4 \pm 0.26 \% \mathrm{O}, 0.3 \pm 0.05 \% \mathrm{C}$, and $7.6 \pm 0.3 \% \mathrm{~N}$. This type of particle, with a Y-enriched core, was only found in $\sim 1 \%$ of the precipitates. The other Ti-O-enriched precipitate, shown in Fig. $6 \mathrm{~b}$ had a composition of $18.5 \pm 1.5$ at. $\% \mathrm{Fe}, 16.4 \pm$ $0.3 \% \mathrm{Cr}, 1 \pm 0.2 \% \mathrm{~W}, 31.0 \pm 0.4 \% \mathrm{Ti}, 13.8 \pm 0.2 \% \mathrm{O}, 2.4 \pm 0.1 \% \mathrm{C}$, and $6.4 \pm 0.2 \% \mathrm{~N}$. Interestingly this precipitate was not found to contain any $\mathrm{Y}$ atoms. The estimated ferrite compositions from several grains for the 5-h-milled condition are listed in Table 1. Marked variations in the solute contents are evident in different grains, indicating that after this short milling time, the solutes were not uniformly distributed. 
In the $20 \mathrm{~h}$ condition, the Ti-O-enriched particles were significantly finer-scaled. Proximity histograms across the interfaces of the precipitates with two different sizes in the material that was milled for $20 \mathrm{~h}$, shown in Fig. 3b, are shown in Fig 7. The compositions of 2-4 nm Ti-Y-O NCs were found to be of 57.7 \pm 1.7 at. $\% \mathrm{Fe}, 25.6 \pm 1.4 \% \mathrm{Cr}, 0.9 \pm 0.2 \% \mathrm{Y}, 0.7 \pm 0.2 \% \mathrm{~W}, 3.8 \pm 0.2 \% \mathrm{Ti}, 8.2 \pm 0.3 \% \mathrm{O}, 0.5 \pm 0.2 \%$ $\mathrm{C}$, and no N . The 4-10 nm Ti-Y-O NCs had a composition of $50.7 \pm 0.7$ at. \% Fe, $21.0 \pm 0.7 \% \mathrm{Cr}, 3.8 \pm$ $0.06 \% \mathrm{Y}, 2 \pm 0.9 \% \mathrm{~W}, 4.8 \pm 0.1 \% \mathrm{Ti}, 10.7 \pm 0.05 \% \mathrm{O}, 0.7 \pm 0.2 \% \mathrm{C}$, and $4.6 \pm 0.2 \% \mathrm{~N}$. However, some larger precipitates were also found, indicating that this $20 \mathrm{~h}$ intermediate milling time was still not sufficient to produce a homogenous solute distribution.

A proximity histogram from one of these larger precipitates is shown in Fig. 8. The coarser precipitate was found to have a composition of $27.0 \pm 0.2$ at. $\% \mathrm{Fe}, 23.7 \pm 0.1 \% \mathrm{Cr}, 1.0 \pm 0.02 \% \mathrm{Y}, 1 \pm 0.05 \% \mathrm{~W}$, $9.7 \pm 0.02 \% \mathrm{Ti}, 28.3 \pm 0.05 \% \mathrm{O}, 0.05 \pm 0.01 \% \mathrm{C}$, and $0.3 \pm 0.02 \% \mathrm{~N}$. The estimated ferrite compositions from several grains of the 20 -h-milled condition are also included in Table 1 . As observed for the 5-h milled condition, marked variations in the solute contents are evident in different grains of the 20-h milled alloy indicating that the milling times up to $20 \mathrm{~h}$ were too short to fully homogenize the solute distributions in the milled flakes and take full benefit of the alloying additions.

The smaller (2-4 nm) precipitates show comparatively high $\mathrm{Fe}$ and $\mathrm{Cr}$ contents (e.g., 58\% Fe, 25\% $\mathrm{Cr}$ ); this is likely an artefact of trajectory aberration in APT [35], which is unavoidable where oxide nanoparticles in a metal matrix are examined. With larger precipitates $(>10 \mathrm{~nm})$ the lower $\mathrm{Fe}$ contents (e.g., 27\%) are probably more accurate, owing to a very small influence of trajectory aberration as the particle sizes increase; cation substitutions are common in ceramics, so the Fe content is possible but certainly not proven. The quantitative nature of trajectory aberration and its influence on composition measurements is still not well known [36], but the trends for solute are what is important to understand NC evolution. 
The results presented here and previous APT and transmission electron microscopy (TEM) studies, have demonstrated that the 14YWT powder milled for $40 \mathrm{~h}$ does not generally exhibit any coarse (i.e., greater than $100 \mathrm{~nm}$ ) precipitates [21]. After consolidation by extrusion and thermal aging of these flakes, three main populations of fine scale precipitates are present in the microstructure. The largest $(20-50 \mathrm{~nm})$ precipitate is a cubic TiX, where $\mathrm{X}$ is a combination of $\mathrm{N}, \mathrm{O}$ and $\mathrm{C}$, and is predominantly found on GBs. Owing to their low number densities, few of these precipitates have been characterized by APT. The solute content is uniform within each precipitate, but the non-metal content $(\mathrm{O}, \mathrm{N}$, and $\mathrm{C})$ varies considerably. The $\mathrm{Y}$ content is typically $<1$ at. $\%$ in these precipitates and they contain a significant level of Fe. A second population of smaller (approximately 5-10 $\mathrm{nm}$ diameter) and higher areal density precipitates was found decorating the GBs [37-38]. In addition, a third dense population of ultrafine scale $\sim 2.0 \pm 0.2 \mathrm{~nm}$ diameter NCs was observed in the grain interior and on GBs. The APT data also indicate that the majority of the $\mathrm{Cr}$ and $\mathrm{W}$ additions are in solid solution in the ferrite matrix, and there are strong enrichments of $\mathrm{Cr}$ and $\mathrm{W}$ between the precipitates on the GBs [21]. Low levels of $\mathrm{C}, \mathrm{P}$ and $\mathrm{Si}$ segregation to the GBs have also been observed in APT data [21].

\section{Discussion}

A comparison of the as-extruded and as-cast NFAs reveals that traditional casting does not produce the desired fine-scale and uniformly distributed precipitate population necessary to produce a highly stable microstructure in 14YWT and related NFAs with excellent properties. Instead, the coarse-grained microstructure consists of a low-solute ferrite phase devoid of any fine-scale precipitates but with a low number density of irregularly shaped precipitates consisting of a 50-100 $\mu \mathrm{m} \mathrm{Y}_{2} \mathrm{Ti}_{2} \mathrm{O}_{7}$ (pyrochlore) phase embedded with a fine-scale $\mathrm{Y}_{3} \mathrm{Al}_{5} \mathrm{O}_{12}$ (yttrium-aluminum garnet) phase.

Mechanical alloying followed by extrusion and annealing can produce the desired nanoscale grains and finely distributed NCs. However, to achieve this goal, milling times of at least $40 \mathrm{~h}$ are required. When shorter milling times of $\sim 5 \mathrm{~h}$ are used (recall that " $5 \mathrm{~h}$ " denotes $5 \mathrm{~h}$-milled flakes, then consolidated and 
annealed into the examined specimens), the microstructure contains a relatively low number density of coarse precipitates. This distribution consumes the alloying elements in a few coarse precipitates, and thereby prevents the formation of the high number density of NCs as the solute content of the ferrite is no longer supersaturated. In the case of $20 \mathrm{~h}$ sample, instead of coarser Ti-Y-O precipitates formed like in the $5 \mathrm{~h}$ sample, finer-scale precipitates are present, presumably due to a more uniform solute distribution within the as-milled flakes prior to the high-temperature consolidation, extrusion, and annealing. After milling for $40 \mathrm{~h}$, this process results in a predominantly uniform dispersion of 2-nm-diameter NCs in the ferrite, and slightly coarser precipitates along the GBs, where the diffusion rate of solutes is likely to be higher due to pipe-diffusion type processes [21]. Milling time, and its concomitant effects of changing the nature and size of the NCs, is likely to heavily modify the NCs ability to serve as beneficial sinks against radiation damage, so optimization of the microstructure is vital for not just mechanical but also irradiation properties, especially considering that many different types of NCs are present even in a single alloy [39]. Milling also has the beneficial effect of refining and maintaining the ultrafine grain size. Longer milling times are anticipated to have limited returns on improving the microstructure, as the precipitate size and number density appears to be near optimal for producing the desires mechanical properties, and longer milling will only serve to increase the production costs, and may result in the introduction of more contaminants $[16,20]$.

This study has revealed that progressively longer milling times were found to produce a more uniform dispersion of the solutes and a more uniform precipitate size and distribution within the ferrite matrix. Empirical observations have also indicated that long milling times of the precursor material $[19,40]$ are needed to achieve a uniform as-milled microstructure. This was also supported by producing 14YWT with additions of $\mathrm{Fe}_{2} \mathrm{O}_{3}$ and $\mathrm{YH}_{2}$ powder instead of $\mathrm{Y}_{2} \mathrm{O}_{3}$ powder [41]. Extended ball milling up to $96 \mathrm{~h}$ improved oxide dispersion, microstructural refinement and mechanical properties as shown by Romanoski et al [42]. Milling times with different mill technologies (i.e., SPEX rather than attritor mills) can be shorter (e.g., $8 \mathrm{~h} \mathrm{[} \mathrm{6]} \mathrm{or} 20 \mathrm{~h}$ [Ref. 43]) due to the high energy density in the processing, but the 
trend to determine a minimum necessary milling time remains due to cost concerns. Studies of high- $\mathrm{Y}_{2} \mathrm{O}_{3}$ (3-15\%) model alloys have revealed that diffraction peaks of $\mathrm{Y}_{2} \mathrm{O}_{3}$ disappear after milling times of 48-100 $\mathrm{h}$ [44-45]. The mechanism becomes more complex with the presence of large amount of yttria in the alloy system. Small amount of the yttria particles is dissolved into the matrix to form a supersaturated solid solution, whereas the remaining oxide particles are transformed to an amorphous compound [46]. However, the relationship between these high yttria model alloys to NFAs with less than $1 \% \mathrm{Y}_{2} \mathrm{O}_{3}$ additions is unclear.

\section{Conclusions}

The microstructure of the as-cast NFA consists of coarse grains of $\alpha$-Fe with $50-100 \mu \mathrm{m}$ irregularly shaped $\mathrm{Y}_{2} \mathrm{Ti}_{2} \mathrm{O}_{7}$ pyrochlore precipitates containing smaller embedded precipitates 3-15 $\mu \mathrm{m}$ YAG crystal structure; these YAG particles may be an artefact of melting in an alumina crucible, given the low bulk$\mathrm{Al}$ level in the starting specimen. In contrast, the microstructure of the 40-h-milled as-extruded and aged condition consisted of ultrafine grains of $\alpha$-Fe with three distributions of precipitates, $\sim 2$-nm-diameter TiY-O-vacancy-enriched NCs, 5-10 $\mathrm{nm} \mathrm{Y}_{2} \mathrm{Ti}_{2} \mathrm{O}_{7}$, and 20-50 $\mathrm{nm} \mathrm{Ti}(\mathrm{O}, \mathrm{C}, \mathrm{N})$ precipitates. The nanohardnesses of the as-cast and as-extruded and aged conditions were also substantially different, i.e., 4 and $8 \mathrm{GPa}$, respectively, due to the different microstructures produced.

These results confirm that the milling time is an important parameter to optimize particle size distribution and number density within the NFA microstructure. At shorter milling times $(5-20 \mathrm{~h})$, the Ti, Y, and O atoms are consumed in lower number densities of coarse precipitates and there are large variations in the solute contents of the ferrite matrix. After a longer milling time $(40 \mathrm{~h})$, a uniform distribution of ultrafine precipitates with high number densities are present in the ferrite., Hence, an optimized long milling time upto $40 \mathrm{~h}$ is needed to achieve desired fine structure, milling time longer than this is not necessary whereas less than $40 \mathrm{~h}$ milling time will produce material with inferior properties. 


\section{Acknowledgements}

Research sponsored by the Materials Sciences and Engineering Division, Office of Basic Energy Sciences, US Department of Energy. The microscopy and APT were conducted as part of a user project at the Center for Nanophase Materials Sciences, which is a DOE Office of Science User Facility. The authors thank Dr. D. T. Hoelzer of Oak Ridge National Laboratory for providing the 14YWT NFA, and Drs. K. G. Field, S. N. Dryepondt, and P. D. Edmondson for discussions and critiques of the manuscript.

\section{References}

[1] A. Certain, K.G. Field, T.R. Allen, M.K. Miller, J. Bently and J.T. Busby, , J. Nucl. Mater., 407 (2010) 2-9

[2] M.K. Miller and D.T. Hoelzer, J. Nucl. Mater., 418 (2011) 307-310.

[3] J. He, F. Wan, K. Sridharan, T.R. Allen, A. Certain, V. Shutthanandan and Y.Q. Wu, J. Nucl. Mater., 455 (2014) 41-45.

[4] K.L. Murty and I. Charit, J. Nucl. Mater., 383 (2008) 189-195.

[5] G.R. Odette, M.J. Alinger and B.D. Wirth, Ann. Rev. Mater. Res., 38 (2008) 471-503

[6] M.J. Alinger, G.R. Odette and D.T. Hoelzer, Acta Mater., 57(2) (2009) 392-406.

[7] S. Ukai, M. Harada, H. Okada, M. Inoue, S. Nomura, S. Shikakura, K. Asabe, T. Nishida and M. Fujiwara, J. Nucl. Mater., 204 (1993) 65-73,

[8] R.L. Klueh, J. Nucl. Mater., 378 (2008) 159-166

[9] D.A. McClintock, D.T. Hoelzer, M.A. Sokolov and R.K. Nanstad, J. Nucl. Mater., 386 (2009) 307311.

[10] M.K. Miller, E.A. Kenik, K.F. Russell, L. Heatherly, D.T. Hoelzer and P.J. Maziasz, Mater. Sci. Eng. A., A353 (2003) 140-145.

[11] C.L. Fu and M.H. Yoo, Mater. Chem. Phys., 32 (1992) 25-36,

[12] C.L. Fu, M. Krcmar, G.S. Painter and X.Q. Chen, Phy. Rev. Lett., 99, (2007) 225502 
[13] M.K. Miller, C.L. Fu, M. Krcmar, D.T. Hoelzer and C.T. Liu, Front. Mater. Sci. China, 3(1) (2009) 9-14.

[14] M. Brocq, B. Radiguet, J.M. Le Breton, F. Cuvilly, P. Pareige, F. Legendre, Acta Mater., 58 (2010) $1806-1814$

[15] L. Dai, Y. Liu and Z. Dong, Powder Technology, 217 (2012) 281-287

[16] C. Suryanarayana, Prog. Mater. Sci., 46 (2001) 1-184

[17] C.C. Koch, Ann.1 Rev. Mater. Sci., 19 (1989) 121-143

[18] B.S. Murty and S. Ranganathan, Int. Mater. Rev., 43 (1998) 101-141

[19] R. Didomizio, S. Huang, L. Dial, J. Ilavsky and M. Larsen, Metall. Mater. Trans. A, 45A (2014) 5409

[20] P.S. Gilman and J.S. Benjamin, Ann. Rev. Mater. Res., 13 (1983) 279-300

[21] M.K. Miller and C.M. Parish, Mater. Sci. Technol., 27 (2011) 729-734

[22] N. J. Cunningham, Y. Wu, G. R. Odette, D. T. Hoelzer and S. A. Maloy, Fusion Reactor Materials Program, DOE, June 30, 54 (2013)

[23] N. J. Cunningham, Y. Wu, A. Etienne, E.M. Haney, G. R. Odette, E. Stergar, D. T. Hoelzer, Y.D. Kim, B.D. Wirth and S. A. Maloy, J. Nucl. Mater., 444 (2014) 35-38

[24] D.J. Larson, P.J. Maziasz, I-S. Kim and K. Miyahara, Scripta Mater., 44 (2001) 359-364

[25] R. Xie, Z. Lu, C. Lu and C. Liu, J. Nucl. Mater., 455 (2014) 554-560

[26] W.C. Oliver and G.M. Pharr, J. Mater. Res., 19 (2004) 3-20.

[27] M.K. Miller and R. G. Forbes, Atom Probe Tomography: The Local Electrode Atom Probe, Springer, New York NY, 2014,

[28] D.J. Larson, T.J. Prosa, R.M. Ulfig, B.P. Geiser and T. F. Kelly, Local Electrode Atom Probe Tomography, Springer, New York NY, 2013

[29] K. Thompson, D. Lawrence, D.J. Larson, J.D. Olson, T.F. Kelly and B. Gorman, Ultramicrosc., 107 (2007) 131-139

[30] M.K. Miller, K.F. Russell and G.B. Thompson, Ultramicrosc., 102 (2005) 287-298 
[31] P.G. Kotula, M.R. Keenan, J.R. Michael, Microsc. Microanal., 9 (2003) 1-17

[32] C.M. Parish, R.M. White, J.M. LeBeau and M.K. Miller, J. Nucl. Mater., 445 (2014) 251-260

[33] M.K. Miller, C.M. Parish and Q. Li, Mater. Sci. Technol., 29 (2013) 1174-1178

[34] M.K. Miller, D.T. Hoelzer and K.F. Russell, Mater. Sci. Forum, 654-656 (2010) 23-28

[35] C. A. Williams, E. A. Marquis, A. Cerezo and G. D. W. Smith, Journal of Nuclear Materials $400(2010) 37$

[36] C.A. Williams, G.D.W. Smith and E.A. Marquis, Ultramicroscopy, 125 (2013)10-17

[37] L. Yao, S.P. Ringer, J.M. Cairney and M.K. Miller, Scripta Mater., 69 (2013) 622-625

[38] M.K. Miller and L. Yao, Current Opinion in Solid State and Materials Science, 17 (2013) 203-210

[39] D. Bhattacharyya, P. Dickerson, G.R. Odette, S.A. Maloy, A. Misra, M.A. Nastasi, Philosophical Magazine, 92(16) ( 2012) 2089-2107.

[40] B. Dousti, R. Mojaver, H.R. Shahverdi and R.S. Mamoory, J. Alloys and Compounds, 577 (2013) 409-416

[41] Y. Wen, Y. Liu, A. Hirata, F. Liu, T. Fujita, Y. Dou, D. Liu, B. Liu, Z. Liu and C.T. Liu, Mater. Sci. Engin. A, 544 (2012) 59- 69

[42] G.R. Romanoski, L.L. Snead, R.L. Klueh and D.T. Hoelzar, J. Nucl. Mater., 283-287 (2000) 642646

[43] M. Saber, W.Z. Xu, L.L. Li, Y.T. Zhu, C.C. Koch, R.O. Scattergood, J. Nucl. Mater., 452 (2014) 223-229

[44] H. Zhang, M.J. Gorley, K.B. Chong, M.E. Fitzpatrick, S.G. Roberts and P.S. Grant, J. Alloys and Compounds, 582 (2014) 769-773

[45] L. Toualbi, M. Ratti, G. Andre, F. Onimus and Y.de Carlan, J. Nucl. Mater., 417 (2011) 225-228

[46] T. Okuda and M. Fujiwara, J. Mater. Sci. Lett., 14 (1995) 1600-1603 
Table 1. Composition of the 14YWT nanostructured ferritic alloy [21], the ferrite phase in the as-cast alloy, and for the different milling times. The balance is iron.

\begin{tabular}{|c|c|c|c|c|c|c|c|c|c|}
\hline Element & & $\mathrm{Cr}$ & $\mathrm{Y}$ & W & $\mathrm{Ti}$ & $\mathrm{O}$ & $\mathrm{C}$ & $\mathrm{Si}$ & $\mathrm{N}$ \\
\hline \multirow[t]{2}{*}{ Bulk } & at. $\%$ & 13.93 & 0.14 & 0.16 & 0.24 & 0.39 & 0.24 & 0.16 & 0.15 \\
\hline & wt. \% & 13.13 & 0.22 & 0.54 & 0.19 & $1140 \mathrm{ppm}$ & $530 \mathrm{ppm}$ & 0.08 & $385 \mathrm{ppm}$ \\
\hline \multicolumn{10}{|l|}{ Ferrite } \\
\hline As-cast & at. $\%$ & $15.9 \pm 1.6$ & $0.03 \pm 0.01$ & $0.52 \pm 0.5$ & $0.07 \pm 0.01$ & $0.04 \pm 0.01$ & $0.03 \pm 0.01$ & $0.07 \pm 0.01$ & $0.02 \pm 0.01$ \\
\hline $5 \mathrm{~h}$ & $\begin{array}{l}\text { Grain } \\
1 \\
2 \\
3 \\
4 \\
5\end{array}$ & $\begin{array}{l}14.8 \pm 0.4 \\
15.5 \pm 0.1 \\
14.9 \pm 0.1 \\
14.4 \pm 0.1 \\
14.7 \pm 0.1\end{array}$ & $\begin{array}{l}0.06 \pm 0.01 \\
0.04 \pm 0.01 \\
0.01 \pm 0.01 \\
0.01 \pm 0.01 \\
0.01 \pm 0.01\end{array}$ & $\begin{array}{l}0.20 \pm 0.01 \\
0.80 \pm 0.03 \\
0.90 \pm 0.02 \\
0.14 \pm 0.01 \\
0.04 \pm 0.01\end{array}$ & $\begin{array}{l}0.06 \pm 0.01 \\
0.03 \pm 0.01 \\
0.02 \pm 0.01 \\
0.11 \pm 0.01 \\
0.42 \pm 0.01\end{array}$ & $\mid \begin{array}{c}0.20 \pm 0.002 \\
0.30 \pm 0.01 \\
0.60 \pm 0.003 \\
0.17 \pm 0.01 \\
0.35 \pm 0.001\end{array}$ & $\begin{array}{c}0.004 \pm 0.004 \\
0.02 \pm 0.01 \\
0.004 \pm 0.002 \\
0.01 \pm 0.01 \\
0.005 \pm 0.01\end{array}$ & $\begin{array}{c}0.05 \pm 0.002 \\
0.09 \pm 0.01 \\
0.04 \pm 0.01 \\
0.05 \pm 0.01 \\
0.03 \pm 0.002\end{array}$ & $\begin{array}{c}0.042 \pm 0.01 \\
0.003 \pm 0.002 \\
0.007 \pm 0.002 \\
0.06 \pm 0.01 \\
0.30 \pm 0.01\end{array}$ \\
\hline $20 \mathrm{~h}$ & $\begin{array}{l}1 \\
2 \\
3 \\
4 \\
5\end{array}$ & $\begin{array}{l}14.0 \pm 0.04 \\
14.2 \pm 0.05 \\
15.2 \pm 0.05 \\
14.4 \pm 0.05 \\
15.9 \pm 0.04\end{array}$ & $\begin{array}{l}0.10 \pm 0.002 \\
0.08 \pm 0.002 \\
0.30 \pm 0.003 \\
0.14 \pm 0.003 \\
0.10 \pm 0.002\end{array}$ & $\begin{array}{l}0.13 \pm 0.01 \\
0.14 \pm 0.01 \\
0.70 \pm 0.01 \\
0.10 \pm 0.01 \\
0.80 \pm 0.01\end{array}$ & $\begin{array}{c}0.03 \pm 0.003 \\
0.30 \pm 0.01 \\
0.50 \pm 0.01 \\
0.30 \pm 0.01 \\
0.20 \pm 0.01\end{array}$ & \begin{tabular}{|c|}
$0.5 \pm 0.002$ \\
$0.44 \pm 0.002$ \\
$1.00 \pm 0.01$ \\
$0.84 \pm 0.001$ \\
$0.30 \pm 0.01$
\end{tabular} & $\begin{array}{c}0.04 \pm 0.001 \\
0.05 \pm 0.002 \\
0.1 \pm 0.004 \\
0.05 \pm 0.002 \\
0.13 \pm 0.004\end{array}$ & $\begin{array}{c}0.07 \pm 0.004 \\
0.02 \pm 0.01 \\
0.25 \pm 0.01 \\
0.06 \pm 0.003 \\
0.24 \pm 0.01\end{array}$ & $\begin{array}{c}0.10 \pm 0.001 \\
0.70 \pm 0.01 \\
0.34 \pm 0.002 \\
0.16 \pm 0.001 \\
0.10 \pm 0.001\end{array}$ \\
\hline $40 \mathrm{~h}$ & $\begin{array}{l}1 \\
2 \\
3 \\
4 \\
5\end{array}$ & $\begin{array}{l}15.5 \pm 0.01 \\
13.6 \pm 0.06 \\
16.0 \pm 0.02 \\
15.7 \pm 0.04 \\
15.6 \pm 0.04\end{array}$ & $\begin{array}{l}0.06 \pm 0.003 \\
0.06 \pm 0.002 \\
0.04 \pm 0.002 \\
0.02 \pm 0.003 \\
0.01 \pm 0.003\end{array}$ & \begin{tabular}{|c|}
$0.75 \pm 0.01$ \\
$0.63 \pm 0.01$ \\
$0.08 \pm 0.002$ \\
$0.03 \pm 0.002$ \\
$0.005 \pm 0.01$
\end{tabular} & $\begin{array}{c}0.07 \pm 0.01 \\
0.10 \pm 0.01 \\
0.14 \pm 0.002 \\
0.08 \pm 0.003 \\
0.08 \pm 0.003\end{array}$ & \begin{tabular}{|c|}
$0.30 \pm 0.01$ \\
$0.40 \pm 0.01$ \\
$0.54 \pm 0.003$ \\
$0.32 \pm 0.004$ \\
$0.21 \pm 0.004$
\end{tabular} & $\begin{array}{c}0.03 \pm 0.003 \\
0.06 \pm 0.004 \\
0.33 \pm 0.003 \\
0.31 \pm 0.01 \\
0.30 \pm 0.01\end{array}$ & $\begin{array}{c}0.11 \pm 0.01 \\
0.14 \pm 0.01 \\
0.44 \pm 0.003 \\
0.40 \pm 0.01 \\
0.35 \pm 0.01\end{array}$ & $\begin{array}{c}0.03 \pm 0.001 \\
0.02 \pm 0.001 \\
0.04 \pm 0.001 \\
0.02 \pm 0.002 \\
0.02 \pm 0.003\end{array}$ \\
\hline
\end{tabular}


Table 2. Compositions of the pyrochlore and YAG phases in the as-cast 14YWT alloy.

\begin{tabular}{|c|c|c|c|c|c|c|}
\hline At. $\%$ & $\begin{array}{c}\text { Pyrochlore } \\
\text { prototype }\end{array}$ & $\begin{array}{c}\text { Pyrochlore } \\
\text { SEM }\end{array}$ & $\begin{array}{c}\text { Pyrochlore } \\
\text { APT }\end{array}$ & $\begin{array}{c}\text { YAG } \\
\text { prototype }\end{array}$ & $\begin{array}{c}\text { YAG } \\
\text { SEM }\end{array}$ & $\begin{array}{c}\text { YAG } \\
\text { APT }\end{array}$ \\
\hline $\mathrm{Ti}$ & 18.2 & $\sim 20$ & 17.7 & n/a & trace & 5.9 \\
$\mathrm{Al}$ & $\mathrm{n} / \mathrm{a}$ & trace & 0.03 & 25 & $\sim 30$ & 19.8 \\
$\mathrm{Y}$ & 18.2 & $\sim 15$ & 11.2 & 15 & $\sim 15$ & 15.2 \\
$\mathrm{O}$ & 63.6 & $\sim 65$ & 68.9 & 60 & $\sim 55$ & 59.1 \\
\hline
\end{tabular}




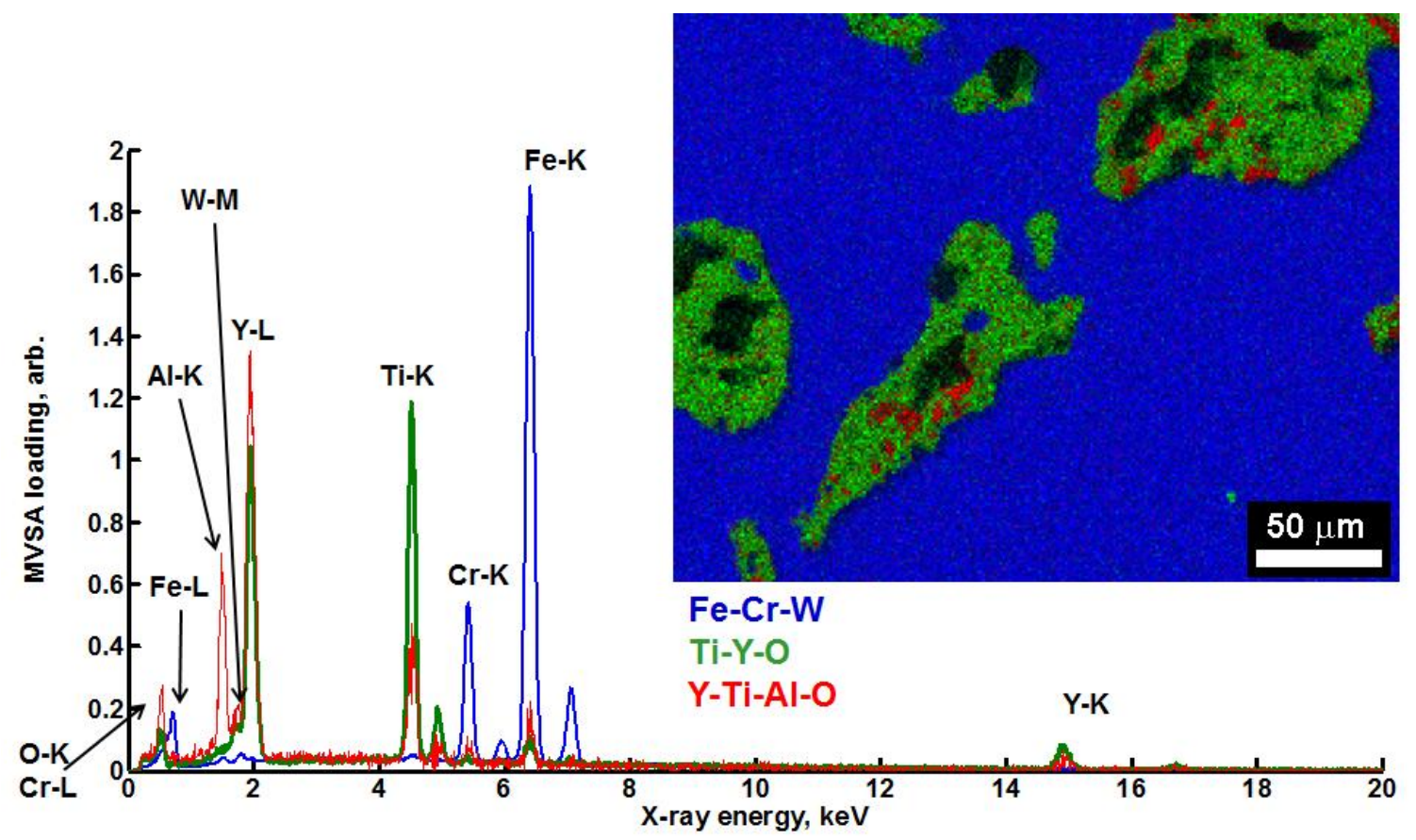

Fig. 1. Multivariate statistical analysis decomposition of SEM EDS X-ray spectrum image. Inset image show false-color score images of three statistically significant components. Loading spectra show the associated elemental response where blue is the $\mathrm{Fe}-\mathrm{Cr}(\mathrm{W})$ matrix, green is the Ti-Y-O phase, and red is the Ti-Al-O(-Y) phase.

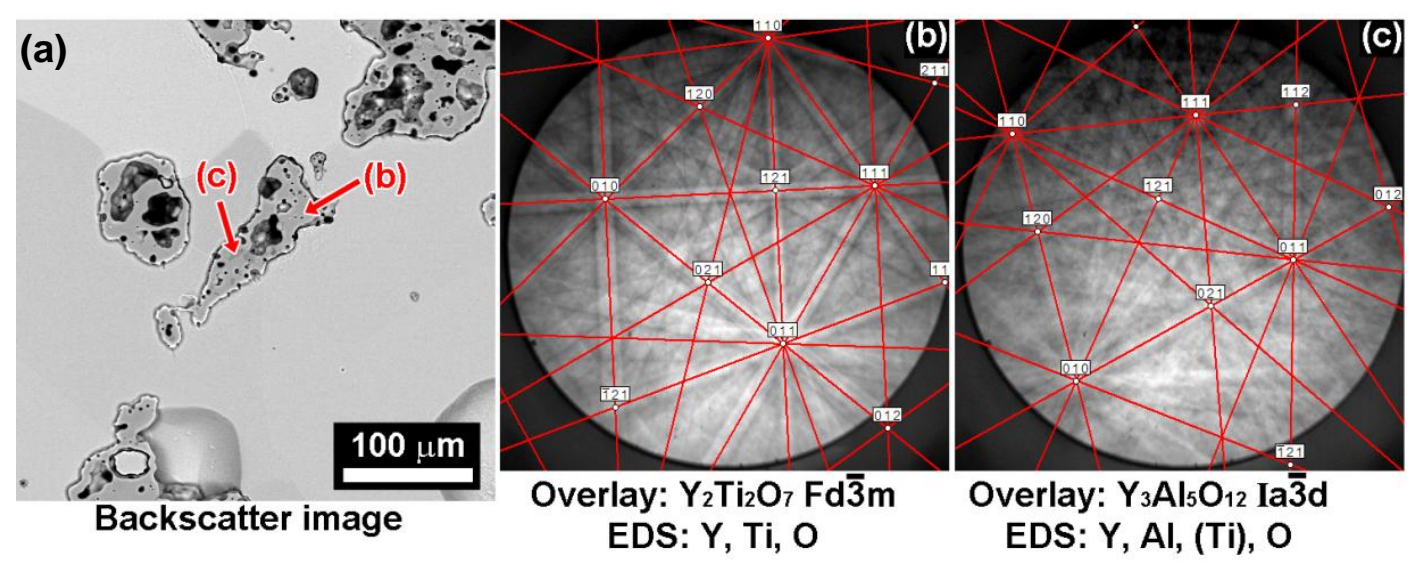

Fig. 2. (a) BSE image of as-cast condition of $14 \mathrm{YWT}$ reveals a ferrite matrix with isolated islands of coarse oxide precipitates. EBSD Kikuchi patterns of b) Ti-Y-O-enriched regions, indexed as $\mathrm{Y}_{2} \mathrm{Ti}_{2} \mathrm{O}_{7}$ pyrochlore, and (c) smaller embedded $\mathrm{Y}$-Ti-Al-O oxides, indexed as $\mathrm{Y}_{3} \mathrm{Al}_{5} \mathrm{O}_{12}$ (YAG). 


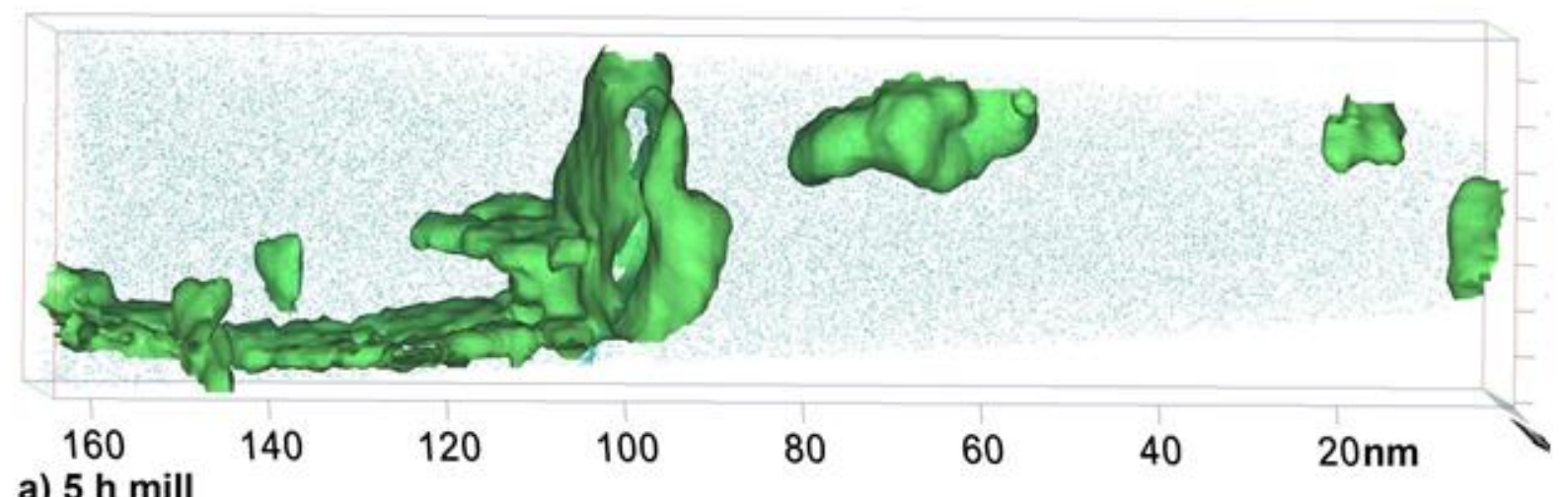

a) $5 \mathrm{~h}$ mill

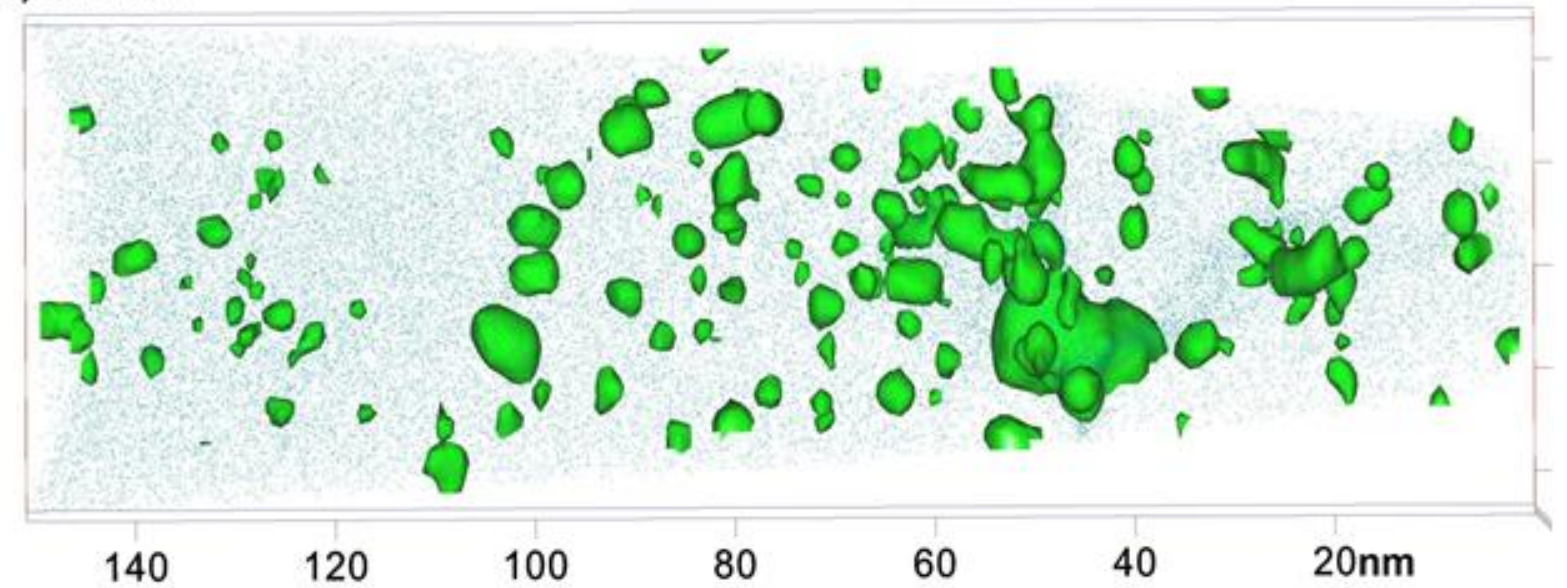

b) $20 \mathrm{~h}$ mill

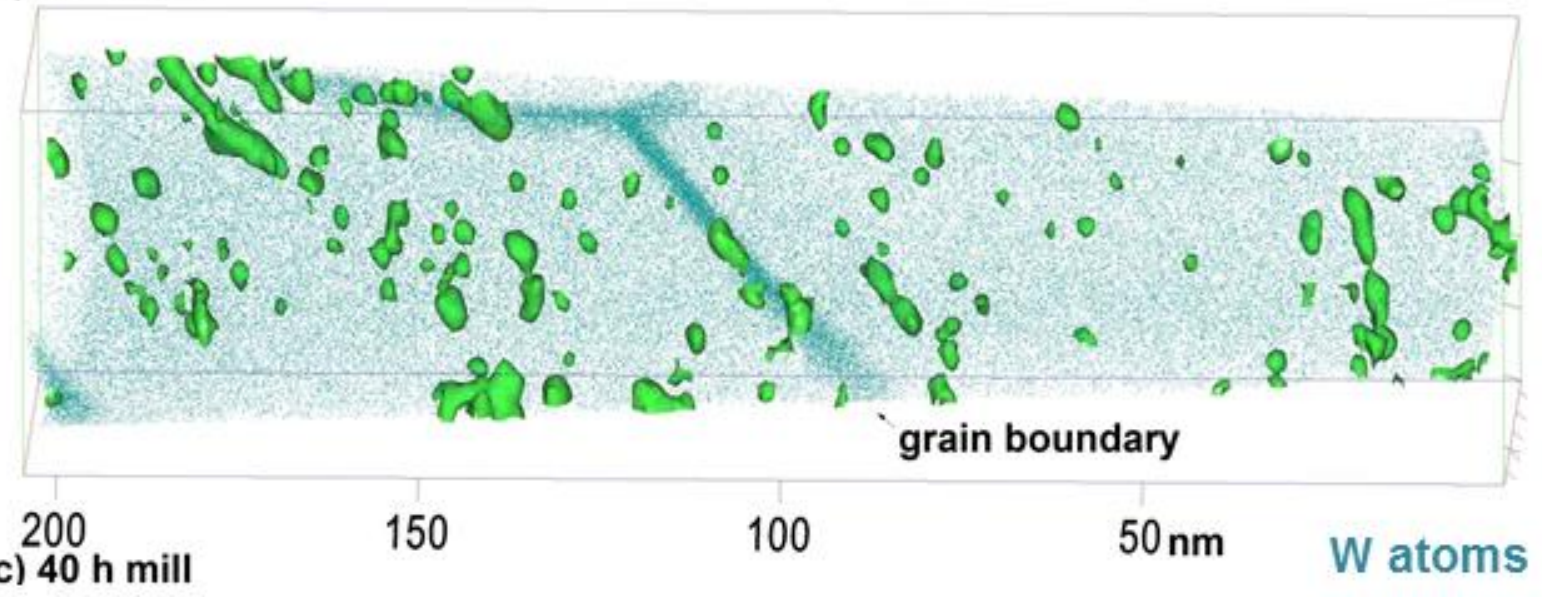

Fig. 3. The microstructures of the 14YWT NFA after milling for 5, 20 and $40 \mathrm{~h}$, extrusion, and aging for $1 \mathrm{~h}$ at $1000{ }^{\circ} \mathrm{C}$. The precipitates are shown by a $3 \% \mathrm{Ti}$ concentration isosurface. The superimposed $\mathrm{W}$ atoms indicate the presence of a GB (viewed edge-on) in the $40 \mathrm{~h}$ milled specimen. 


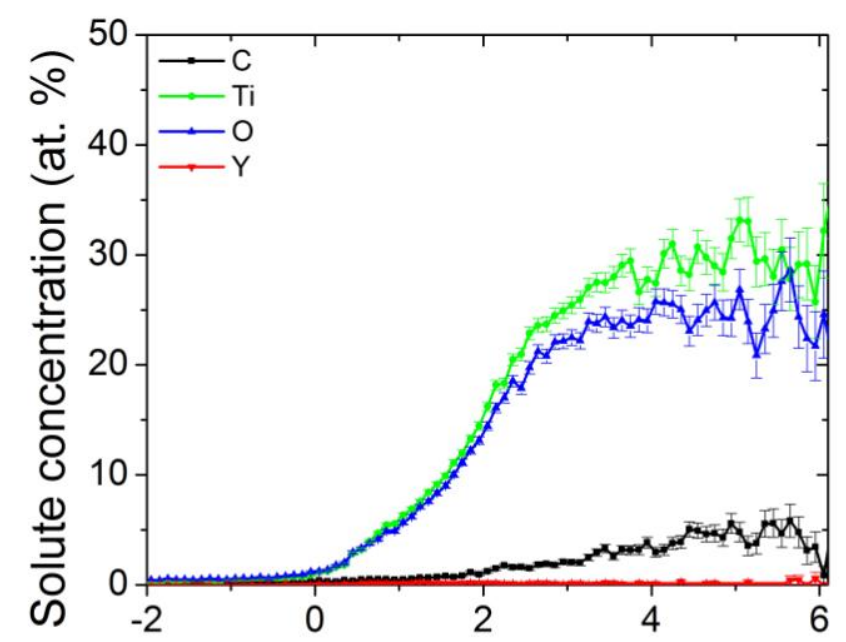

a)

Distance $(\mathrm{nm})$

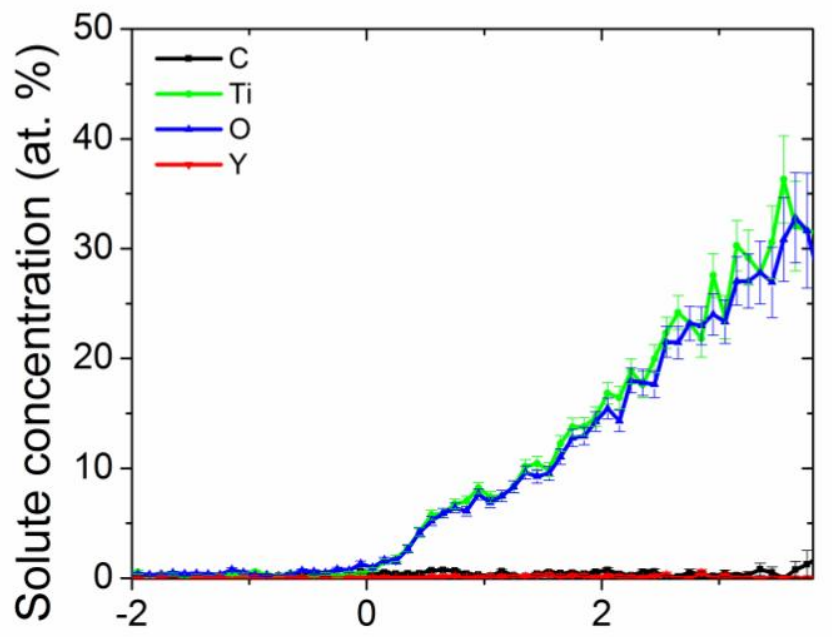

b) Distance $(\mathrm{nm})$

Fig. 4. APT proximity histograms from the $5 \mathrm{~h}$ milled 14YWT NFA showing the solute partitioning of Ti, $\mathrm{Y}, \mathrm{O}$, and $\mathrm{C}$ between the ferrite phase and 2 coarse precipitates, (a) and (b) 


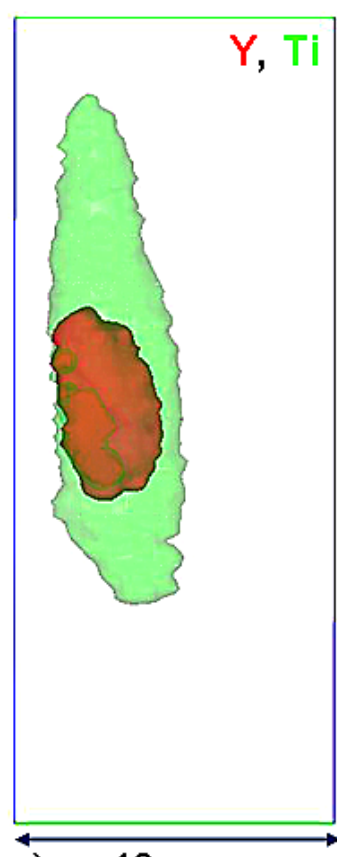

a) $40 \mathrm{~nm}$

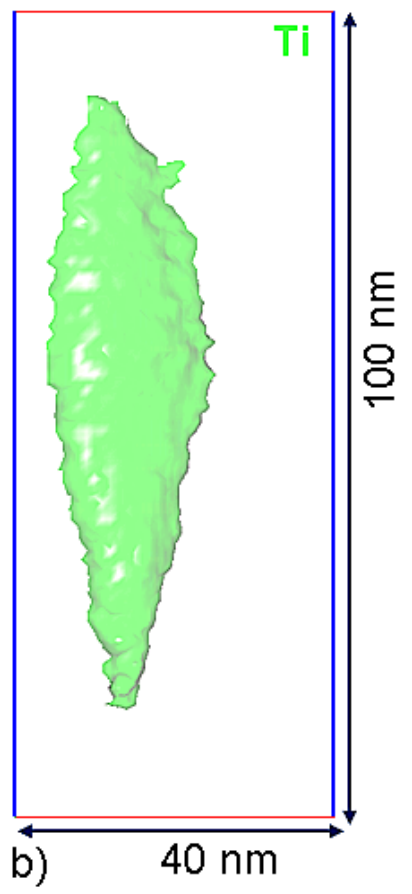

Fig. 5. (a) $1 \% \mathrm{Ti}$ (green) and $2.8 \% \mathrm{Y}$ (red) concentration isosurfaces of a coarse precipitate from the 14YWT NFA after milling for $5 \mathrm{~h}$ with a Y-enriched core region, and (b) a $2 \% \mathrm{Ti}$ (green) concentration isosurface of coarse precipitate with no Y-enriched core. 


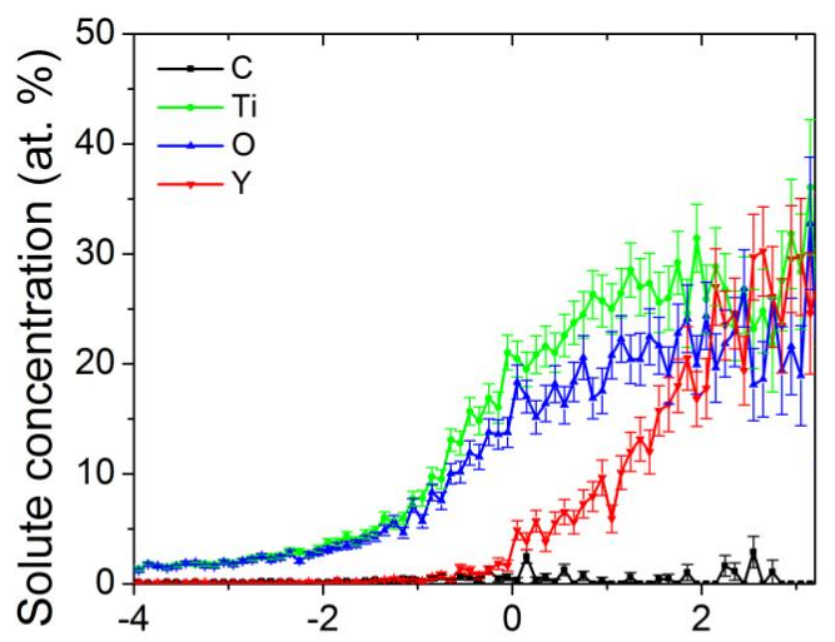

a) Distance $(\mathrm{nm})$

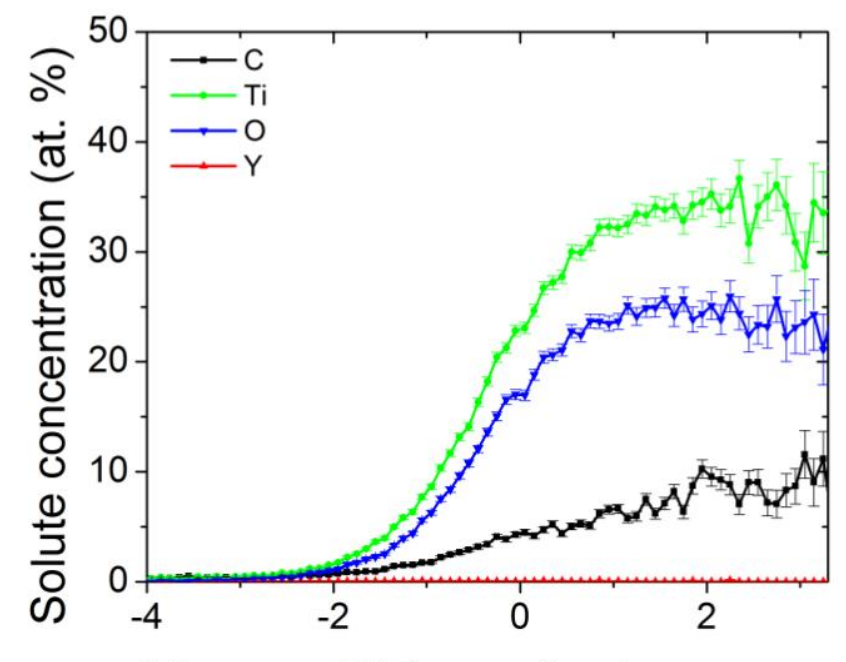

b) Distance $(\mathrm{nm})$ 
Figure 6. APT proximity histograms from the $5 \mathrm{~h}$ milled 14YWT NFA showing the solute partitioning of $\mathrm{Ti}, \mathrm{Y}, \mathrm{O}$, and $\mathrm{C}$ (a) between the ferrite phase and a Y-enriched precipitate, and (b) between the ferrite phase and a TiO- enriched precipitate with no $\mathrm{Y}$ enrichment.

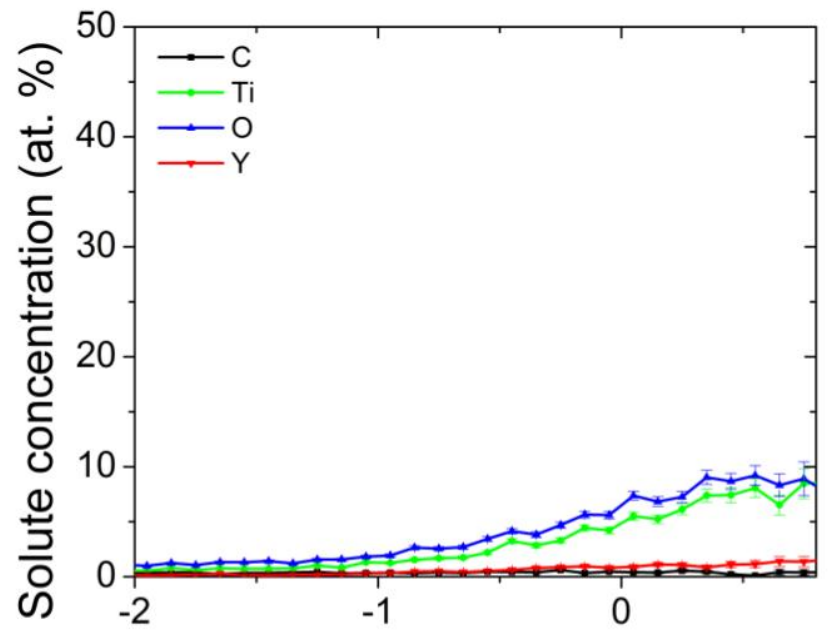

a) Distance $(\mathrm{nm})$

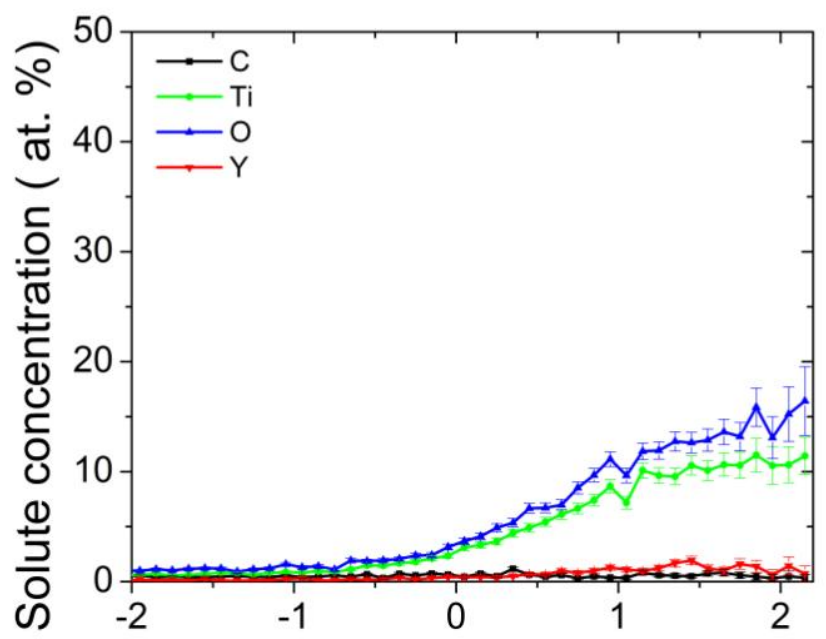

b) Distance $(\mathrm{nm})$

Figure 7. APT proximity histograms from the $20 \mathrm{~h}$ milled 14YWT NFA showing the solute partitioning of Ti, Y, O, and $\mathrm{C}$ between (a) the ferrite phase and the $2-4 \mathrm{~nm}$ diameter Ti-Y-O NCs, and (b) between the ferrite phase and 4-10 nm diameter Ti-Y-O NCs. 


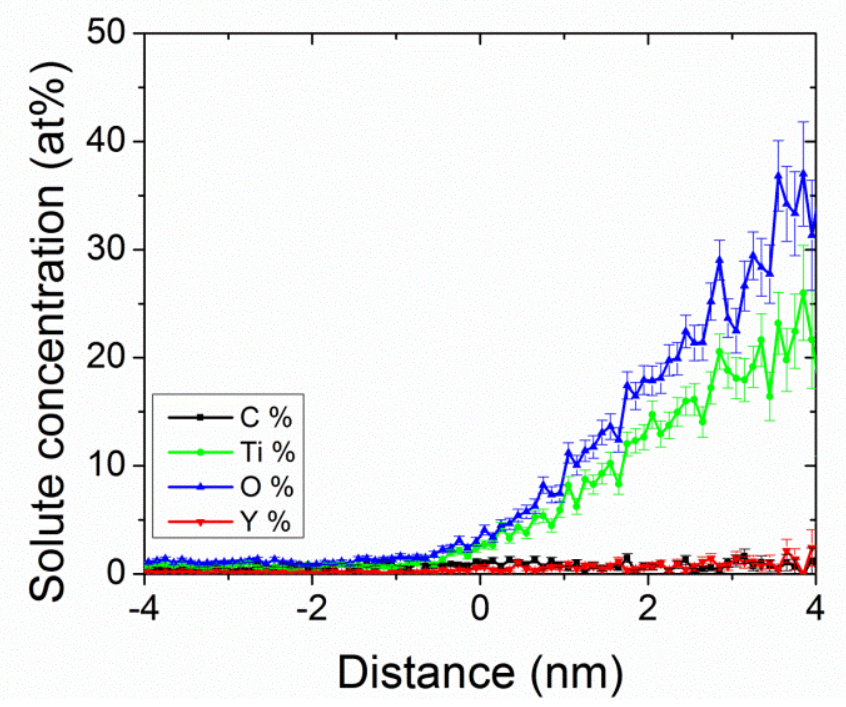

Figure 8. APT proximity histogram from the $20 \mathrm{~h}$ milled 14YWT NFA showing the solute partitioning of $\mathrm{Ti}, \mathrm{Y}, \mathrm{O}$, and $\mathrm{C}$ between the ferrite phase and a large Ti-Y-O-enriched precipitate. 